\title{
ELEMENTOS DA RELAÇÃO COM O SABER DE ESTUDANTES EGRESSOS DE UMA LICENCIATURA EM FÍSICA
}

\author{
BRUNO DOS SANTOS SIMÕES' * \\ https://orcid.org/0000-0002-6956-3974 \\ JOSÉ FRANCISCO CUSTÓDIO" * * \\ https://orcid.org/0000-0003-3835-8086
}

RESUMO: A pesquisa teve como objetivo analisar elementos da relação com o saber estabelecida por egressos de um curso de Licenciatura em Física. Pautados na Teoria da Relação com o Saber de Bernard Charlot evidenciamos aspectos das dimensões identitária, social e epistêmica que influenciaram a permanência deste grupo na graduação. Utilizamos como meio de coleta de dados um questionário enviado por e-mail para 243 egressos. Os dados produzidos foram processados com auxílio da Análise Textual Discursiva (ATD). Os resultados apontam que os principais fatores que contribuíram para a permanência no curso foram: motivação intrínseca, apesar das adversidades externas; sucesso nas avaliações; estabelecimento de uma identidade com a Física ou com a docência em Física; e o suporte da Universidade, principalmente, por meio de projetos que ofereciam auxílio financeiro.

Palavras-chave: Licenciatura em Física. Permanência na graduação. Relação com o saber. Motivação para carreira.

\section{ELEMENTOS DE LA RELACIÓN CON EL SABER DE EGRESOS DE UNA CARRERA DE FORMACIÓN DOCENTE EN FÍSICA}

RESUMEN: La investigación tuvo como objetivo analizar los elementos de la relación con el saber establecida por egresos de la carrera de Formación Docente en Física. Guiados por la Teoría de la Relación con el Saber de Bernard Charlot, evidenciamos los aspectos de las dimensiones identitaria, social y epistémica que influyeron en la permanencia de este grupo en la carrera universitaria. Utilizamos como medio de recolección de datos un cuestionario enviado por correo electrónico a 243 egresos.

\footnotetext{
*Doutor em Educação Científica e Tecnológica pela Universidade Federal de Santa Catarina (UFSC). Professor Pesquisador do Programa de Pós-Graduação em Ensino de Ciências e Matemática da Universidade Federal da Grande Dourados (PPGECMat/UFGD). E-mail: profsimoesfisica@gmail.com

**Doutor em Educação Científica e Tecnológica pela Universidade Federal de Santa Catarina (UFSC). Professor Pesquisador do Programa de PósGraduação em Educação Científica e Tecnológica (PPGECT/UFSC). E-mail: j.custodio@ufsc.br
}

I Universidade Federal da Grande Dourados, Programa de Pós-Graduação em Ensino de Ciências e Matemática, Dourados, MS - Brasil.

II Universidade Federal de Santa Catarina, Programa de Pós-Graduação em Educação Científica e Tecnológica, Florianópolis, SC - Brasil. 
Se procesaron los datos producidos con el auxilio del Análisis Textual Discursivo (ATD). Los resultados apuntan que los principales fatores que contribuyeron a la permanencia en el curso fueron: motivación intrínseca, a pesar de las adversidades externas; éxito en las evaluaciones; establecimiento de una identidad con la Física o con la docencia en Física; y el apoyo de la Universidad, principalmente, por medio de proyectos que ofrecían auxilio financiero.

Palabras clave: Formación Docente en Física. Permanencia en la carrera universitaria. Relación con el saber. Motivación para la carrera.

\section{ELEMENTS OF THE RELATION WITH KNOWLEDGE OF STUDENTS UNDERGRADUATED IN THE PHYSICS COURSE}

ABSTRACT: The research had as objective to analyze elements of the relationship with knowledge established by Physics undergraduate courses. Based on Bernard Charlot's Theory of Relationship with Knowledge, we highlight aspects of the identity, social and epistemic dimensions that influenced the permanence of this group in graduation. As a way of collectioning data, we used a questionnaire sent by email to 243 graduates. The data produced were processed with the assistance of Textual Discourse Analysis (TDA). The results show that the main factors that contributed to the permanence in the course were: intrinsic motivation, despite external adversities; success in evaluations; establishing an identity with Physics or teaching Physics; University support, mainly through projects that offered financial assistance.

Keywords: Physics degree. Permanence in graduation. Relationship with knowledge. Career's motivation. 


\section{INTRODUÇÃO}

A escassez de professores de Física vem sendo abordada na literatura em Educação Científica sob diferentes perspectivas. Dentre elas, surgem pesquisas que focam na evasão do curso e nas causas para tal decisão por parte dos estudantes, tais como: a maioria dos estudantes manterem uma rotina de estudo e trabalho concomitantes, sua origem escolar em escolas precárias, o sistema de avaliação que remetia a altos índices de reprovação, entre outros (LIMA JUNIOR, 2013; KUSSUDA, 2017). Contudo, apesar de ser um aspecto importante a ser investigado, há outros motivos que também impactam diretamente na falta de professores habilitados atuantes na docência em Física, entre eles, a percepção de estudantes com relação ao ingresso e a permanência no curso (porque ingressar e porque permanecer).

Nesse sentido, ao se basearem em teorias sociais da motivação, Simões, Custódio e Rezende-Junior (2016) trataram sobre o porquê ingressar em um curso de Licenciatura em Física. Os autores argumentam que a busca em reviver experiências emocionais positivas e do interesse vivenciadas ao longo do período escolar é um aspecto motivador presente na fala de estudantes recém-ingressantes no curso. Identificaram que uma das condições presentes na escolha, mas também na persistência dos licenciandos em se manter no curso é o interesse construído ao longo da vida escolar pregressa e como a licenciatura se relaciona com as metas estabelecidas por eles, propiciando bem-estar. Isto evidencia que os fatores motivacionais são importantes para compreensão do problema da evasão da licenciatura em Física.

Similarmente, à luz da Psicanálise, Arruda e Ueno (2003) ao investigarem sobre o ingresso, permanência e evasão no curso de Física em uma Universidade estadual, destacam que os estudantes são confrontados com diferentes fatores que exercem impactos positivos e negativos em sua permanência na graduação. Como elementos positivos nesse processo ressaltam: a percepção de que está tendo um bom aprendizado; o apoio da família ao longo do curso; uma boa relação com os amigos de curso; e um bom relacionamento com os docentes.

Sob outra perspectiva, Venturini (2007) argumenta que as teorias sociais da motivação, quando centradas em abordagens quantitativas e fragmentadas, distantes das condições reais e contextuais de produção de sentidos e atitudes pelos indivíduos, não forneceriam subsídios suficientes para compreender um processo com tantas variáveis, como é o caso da permanência em um curso de graduação. Assim, o autor sugeriu que a teoria da relação com o saber, de Charlot (2000), seria capaz de propor o olhar necessário para compreender situações de envolvimento/engajamento dos estudantes em suas atividades.

Nesse sentido, Feitosa (2013) utilizou a teoria da relação com o saber para compreender os vínculos que estudantes ingressantes em uma Licenciatura em Física construíram, de tal modo que optaram por esse curso. A autora mostra que a construção de uma forte relação com os saberes da Física durante o período escolar foi importante na escolha de curso por parte dos licenciandos, e que a permanência no curso, entre outros fatores, também esteve associada ao estabelecimento de uma identidade com a Física e com a docência. 
Acreditamos que o problema da evasão dos cursos de Licenciatura em Física pode ser mais bem interpretado com uma investigação centrada nas relações com saber construídas por egressos, já que eles chegaram à conclusão do curso, mantendo-se persistentes e superando as dificuldades encontradas, podendo oferecer um olhar diferenciado sobre o problema. Pretendemos, portanto, responder a seguinte questão de pesquisa: Quais os principais elementos da relação com o saber estabelecida por egressos de um curso de Licenciatura em Física?

\section{ALGUNS ELEMENTOS DA RELAC̣̃̃O COM O SABER}

Ao buscarem analisar o objeto "fracasso escolar", Bernard Charlot e sua equipe de pesquisadores da Educação, Socialização e Coletividades Locais (ESCOL), ${ }^{1}$ desenvolveram argumentos defendendo a ideia de que não seria possível analisar o fracasso escolar enquanto objeto, mas sim as possíveis situações de fracasso.

Dessa forma, a compreensão de como os sujeitos se relacionam com os diferentes saberes passou a ser objeto de investigação do grupo. Com isso, Charlot (2000) estabeleceu que a relação dos sujeitos com o saber passa por uma relação consigo mesmo, com os outros e com o mundo. Essas relações, por sua vez, se apresentam em três dimensões: uma epistêmica, outra identitária e outra social. Para o autor, o saber é construído em relações coletivas (históricas) das atividades humanas, e, como tal, está submetido a processos de validação, capitação e transmissão. Dessa forma, é produto de relações epistemológicas entre os sujeitos.

Charlot (2000) entende que a relação epistêmica com o saber diz respeito à apropriação, de forma ativa, dos saberes pelos sujeitos no mundo em que vivem. Sua ênfase está na atividade humana em busca de um objeto, o saber.

Da mesma forma que toda relação com o saber apresenta uma dimensão epistêmica, qualquer relação com o saber também comporta uma dimensão de identidade com o saber: "aprender faz sentido por referência à história do sujeito, às suas expectativas, às suas referências, à sua concepção da vida, às suas relações com os outros, à imagem que tem de si e à que quer dar a si e aos outros" (CHARLOT, 2000, p. 72).

Charlot (2000) explica essa relação de identidade para tratar da relação que o sujeito constrói consigo próprio em relação ao saber. A esse sentido, o autor comenta que situações de sucesso ou fracasso escolar podem acarretar relações distintas do sujeito consigo mesmo. Assim, a relação identitária também está atrelada à dimensão relacional. Ou seja, ao se relacionar com outros, com o mundo, o sujeito constrói sua relação com o saber.

Compreender um teorema matemático é apropriar-se de um saber (relação com o mundo), sentir-se inteligente (relação consigo), mas, também, compreender algo que nem todo o mundo compreende, ter acesso a um mundo que é partilhado com alguns, mas, não, com todos, participar de uma comunidade das inteligências (relação com o outro) (CHARLOT, 2000, p. 72).

É possível observar esse efeito em atividades durante a graduação em Física. Resolver, ou não, a lista de exercícios de Cálculo e de Física I fornece 
elementos para que os estudantes construam sua relação com o saber da Física ao longo do curso; relação que pode ser no sentido de pertencimento, no caso de positivo para a resolução, ou, se negativo, de exclusão.

Por fim, a concepção de sujeito inacabado e que atua ativamente no mundo em que vive leva à conclusão de que a relação com o saber é uma ligação com o saber, como o sujeito se relaciona/se liga ao saber. É uma apropriação do mundo, pelo sujeito, em um determinado tempo. A relação com o saber é uma relação com o mundo, consigo mesmo e com os outros (CHARLOT, 2000).

Outro ponto que podemos destacar está ligado à relação do sujeito com o outro. É comum ouvirmos um discurso que diga "gosto de Geometria Analítica, pois o professor é muito bom”. Ou, ainda, "não gosto de Cálculo porque o professor não explica bem". Charlot (2000, p. 73) comenta que a relação com essas disciplinas, nesse caso, está na dependência da relação com o docente e da relação do estudante consigo mesmo: "a relação com o mundo depende da relação com o outro e da relação consigo. Está claro que as questões aqui imbricadas são ao mesmo tempo epistêmicas e de identidade" (p.73).

Charlot (2000) argumenta que estudar a relação com o saber significa estudar a relação que pessoas, lugares, objetos, conteúdos de pensamento, situações, normas etc. têm no processo do aprender e do saber. Nessas condições, o autor lembra de outra figura da relação com o saber, a social. Para compreender a relação de um sujeito com o saber, devemos levar em consideração a relação dele com sua família, amigos, professores, centros de ensino etc. É importante, também, que se observe a origem social deste sujeito, as mudanças no mercado de trabalho, a situação socioeconômica do país, entre outras (CHARLOT, 2000).

Essa relação social com o saber fica mais evidente na seguinte afirmação de Charlot:

Quando um indivíduo aprende no seio de uma instituição, ele só poderá ser 'bom aluno' caso se adapte à relação com o saber definida pela instituição (pelo papel que ela atribui a esse saber, pela organização do currículo e das práticas de ensino etc.) (CHARLOT, 2001, p. 18).

Ao considerar essa afirmação em um contexto de estudantes de Licenciatura em Física, é possível observar que a relação com o saber desses alunos será fortemente influenciada pelas tradições do curso, visto que há uma necessidade de adaptação por parte dos estudantes a questões que estão postas (currículo, práticas de ensino, conhecimentos universais etc.).

Nesse sentido, ao relacionarmos as discussões acerca da permanência dos estudantes no curso de Licenciatura em Física de uma dada instituição com a teoria da relação com o saber, os apontamentos deste trabalho vão ao encontro de evidenciar elementos das dimensões: epistêmica, relacionada a aspectos ligados ao conhecimento, à importância, ao valor e à relevância que se emprega a ele; consigo mesmo ou identitária, que diz respeito à motivação, às crenças e às atitudes; com os outros ou social, uma aproximação às relações sociais que os sujeitos vivem.

$\mathrm{Na}$ dimensão epistêmica, um aspecto relevante aos nossos objetivos é a relação que professores e alunos desenvolvem com o conhecimento. Douady (1994) 
estudou a relação com o saber da Matemática para estudantes e professores. A autora corrobora Charlot (2000) ao afirmar que estudantes e professores atribuem sentidos distintos ao conhecimento. Douady completa argumentando que:

Isso exige que esses alunos possam entrar em uma atividade intelectual e que eles sejam convencidos que isso vale a pena. Não somente de ponto de vista de sua inserção na escola, mas também de um ponto de vista social e cultural (DOUADY, 1994, p. 35).

Nesse sentido, um aspecto relevante apontado por Douady diz respeito às expectativas que os estudantes têm em relação ao conhecimento e à instituição. A autora lembra que, caso essas expectativas não sejam atendidas, esses estudantes podem rejeitar o saber que está sendo estudado, além de uma possível rejeição à escola (DOUADY, 1994). Em relação à pesquisa que desenvolvemos, interessou-nos, particularmente, a importância, a relevância e o valor que os licenciandos dão ao conhecimento.

Esse ponto também se relaciona com a dimensão identitária do saber, pois a relação que os indivíduos constroem com o saber está atrelada à relação que estabelece com os outros e com o mundo (CHARLOT, 2000), uma vez que a relação com o conhecimento está fortemente imbricada às crenças, motivações pessoais e aos afetos.

Podemos observar um aspecto social, devido à mudança do público que ingressa nas Universidades brasileiras a partir do início dos anos 2000, em que pessoas oriundas de classes C e D (GATI, 2009) passam a ter mais acesso aos cursos superiores. Os docentes são confrontados com essa alteração de perfil e frente a essa situação podem buscar superar as adversidades que surgirão ou não tomarem nenhuma atitude a fim de manter as tradições universitárias. Charlot (2005) discute situação semelhante ao falar da abertura da escola a grupos cada vez mais heterogêneos e de como os docentes são relutantes a essas mudanças, pois isso também implica em alterações em seus perfis.

Pelo exposto, entendemos que a teoria da relação com o saber de Charlot contribuiu com esta investigação, especialmente no sentido de entender a relação que os licenciandos constroem com os conhecimentos, com os colegas, com os professores e com a Universidade, a fim de verificar aspectos relativos à sua permanência no curso.

\section{ASPECTOS METODOLÓGICOS DA PESQUISA}

Pautados nos apontamentos anteriores, elaboramos um questionário, via Google Forms, que foi submetido por e-mail para todos os estudantes egressos do curso de Licenciatura em Física, do primeiro semestre de 2004 ao primeiro semestre de 2014, da Universidade Federal de Santa Catarina (UFSC). A referida instituição foi escolhida por ser a primeira a ofertar o curso no estado de Santa Catarina e por ser o local de doutoramento de um dos autores. A relação de estudantes foi obtida junto à secretaria do curso de Física. A coleta dos dados foi realizada durante 3 meses no ano de 2015.

As questões do instrumento foram organizadas em quatro grupos, conforme o quadro a seguir: 
Quadro 1. Questões do instrumento de coleta de dados

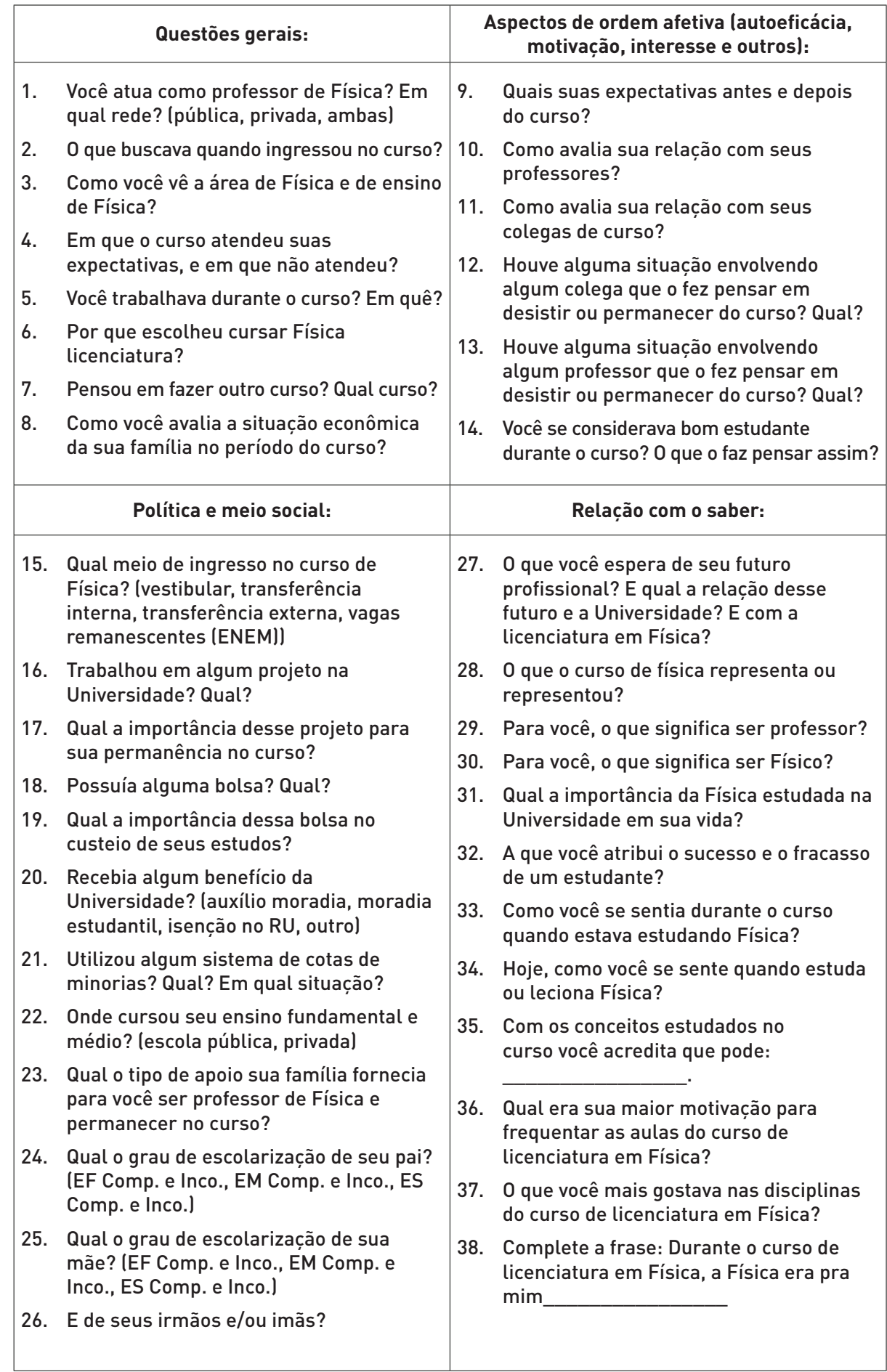

Fonte: Os autores 
Além das questões disponíveis no quadro, também perguntamos alguns dados pessoais como: nome, idade, gênero, ano de ingresso e ano de conclusão do curso. O instrumento que os participantes receberam continha todas essas questões. Porém, com organização e apresentação diferentes.

$\mathrm{Na}$ construção do instrumento, buscamos em outras investigações, que apresentavam algum grau de semelhança, elementos que pudessem subsidiar nossa argumentação em torno da questão central. Dessa forma, o questionário teve por premissa os seguintes aspectos: as relações interpessoais entre estudante-docente e estudante-estudante (UENO, 2013; ARRUDA; UENO, 2003); aspectos sociopolíticos, como questões de moradia, alimentação, transporte, custeio do curso, entre outros (CUNHA; TUNES; SILVA, 2001; CISLAGHI, 2010; KUSSUDA, 2012); elementos da relação com o saber físico e pedagógico (ANAHÍ DA SILVA, 2011; FEITOSA, 2013; da SILVA, 2012); as crenças dos estudantes (SIMÕES; CUSTÓDIO; REZENDEJUNIOR, 2016); além de elementos gerais, como gênero, idade, entre outros.

Para fins de validação, o questionário passou por análise de três pesquisadores em Educação em Ciências, e foi respondido por três egressos do curso de Licenciatura em Física da UFSC que receberam o instrumento por e-mail. Tal procedimento contribuiu para mensurarmos sua capacidade em coletar informações pertinentes ao problema proposto e corrigir eventuais falhas (questões que geravam dúvidas quanto ao seu teor, questões duplicadas, questões sem função etc.).

Nosso foco foi um grupo de 243 egressos do curso de Licenciatura em Física da UFSC. Destes, obtivemos retorno de 26 egressos, aproximadamente $10,7 \%$ do total. A Tabela 1 traz alguns dados relevantes para a compreensão das análises que serão desenvolvidas no artigo. Cabe lembrar que essas informações foram obtidas em 2015 e que o ingresso no curso de Licenciatura ocorreu por meio de vestibular anual.

Tabela 1. Informações gerais dos egressos

\begin{tabular}{cccc}
\hline Egresso & Idade $^{2}$ & Ingresso em & Concluinte em \\
\hline P1 & 32 & 2006 & 2014 \\
\hline P2 & 26 & 2006 & 2009 \\
\hline P3 & 27 & 2005 & 2008 \\
\hline P4 & 30 & 2007 & 2008 \\
\hline P5 & 33 & 2006 & 2007 \\
\hline P6 & 28 & 2006 & 2010 \\
\hline P7 & 32 & 2008 & 2010 \\
\hline P8 & 32 & 2001 & 2005 \\
\hline P9 & 25 & 2009 & 2013 \\
\hline P10 & 34 & 2001 & 2004 \\
\hline P11 & 32 & 2008 & 2008 \\
\hline
\end{tabular}




\begin{tabular}{llll}
\hline P12 & 57 & 2007 & 2010 \\
\hline P13 & 35 & 2004 & 2005 \\
\hline P14 & 35 & 2002 & 2005 \\
\hline P15 & 32 & 2004 & 2006 \\
\hline P16 & 36 & 2006 & 2007 \\
\hline P17 & 37 & 1999 & 2004 \\
\hline P18 & 31 & 2003 & 2006 \\
\hline P19 & 28 & 2009 & 2011 \\
\hline P20 & 29 & 2010 & 2012 \\
\hline P21 & 26 & 2006 & 2011 \\
\hline P22 & 41 & 2001 & 2005 \\
\hline P23 & 27 & 2008 & 2009 \\
\hline P24 & 32 & 2004 & 2009 \\
\hline P25 & 32 & 2005 & 2008 \\
\hline P26 & 36 & 2001 & 2004 \\
\hline
\end{tabular}

Fonte: 0 s autores.

É preciso destacar que ao longo do período analisado (2004 a 2014) houve uma mudança no currículo do curso no ano de 2009. Desta forma, podemos compreender melhor alguma das respostas dos egressos, visto que aqueles que ingressaram antes de 2009 concluíram a Licenciatura com o currículo instituído em 1994, já aqueles que ingressaram após este ano tiveram sua formação no currículo atual do curso, proposto em $2009 .^{3}$

O currículo de 1994, inicialmente, continha 300 horas de atividades de formação docente, a partir do $5^{\circ}$ semestre, entre as quais destacamos as disciplinas de: Instrumentação para o Ensino de Física; Metodologia de Ensino de Física; além de Prática de Ensino de Física. Contudo, ao longo dos anos o currículo foi reformulado, por força de determinações do Conselho Nacional de Educação (CNE) que instituiu a Resolução 01/2002, que trata das Diretrizes curriculares Nacionais para a Formação de Professores de Educação Básica; a Resolução 02/2002, que institui a carga horária dos cursos de Licenciatura; e a Resolução 09/2002 que estabelece as Diretrizes Curriculares para os cursos de Bacharelado e Licenciatura em Física.

A Resolução 02/2002 do CNE, em particular, trazia como exigência a composição de 400 horas de Prática como Componente Curricular, além de 400 horas de Estágio Supervisionado. Tal determinação entrou em vigor no curso justamente no ano de 2004. Tais mudanças trouxeram nova roupagem ao curso, o que, por vezes, fez com que surgissem novos desafios aos professores à época, em especial, pela necessidade de articular, desde o início do curso, as disciplinas de formação docente. Com o amadurecimento de tais mudanças, a passagem de 300 para 800 horas de atividades voltadas à formação docente, além das influências 
que a pesquisa na área de Ensino de Ciências trouxe para os docentes do curso, em 2009 foi instituído um novo Projeto Político Pedagógico.

A análise dos questionários foi feita à luz da Análise Textual Discursiva (MORAES; GALIAZZI, 2007). A ATD é descrita como um processo que se inicia com a fragmentação e desconstrução do corpus da pesquisa. Nesse processo de compreensão, destaca-se a relação existente entre a leitura e a significação. Um texto possibilita encontrar outros significados que são influenciados pelas leituras anteriores do autor e dos referenciais aos quais ele está imerso. Durante o processo de desconstrução e reconstrução do corpus, destacamos os elementos da dimensão Epistêmica, Social e Identitária da relação com o saber, além dos aspectos de ordem afetiva dos egressos, tais como as crenças de autoeficácia.

Cabe ressaltar ainda que este trabalho foi submetido ao Comitê de Ética em Pesquisa com Seres Humanos da UFSC, por meio da Plataforma Brasil, seguindo as normativas da Resolução no 466/2012 do Conselho Nacional de Saúde (CNS). A proposta foi considerada aprovada pelo comitê sob o número 1.355.563.

\section{DIMENSÕES DA RELAÇÃO COM O SABER DOS EGRESSOS EM FÍSICA DA UFSC}

\section{Dimensão identitária com a física}

A relação identitária com o saber conecta-se à percepção do sujeito frente ao saber. Além disso, Douady (1994) trouxe à discussão aspectos da percepção e expectativas dos estudantes em relação à sua instituição de ensino e ao conhecimento a ser estudado. Dessa forma, o engajamento em relação a determinado saber pode ser maior ou menor (CHARLOT, 2000).

$\mathrm{Na}$ condição de perceber-se no curso, ao ser questionado sobre o sucesso ou fracasso de um estudante, tivemos a seguinte afirmação de um dos egressos:

O aluno precisa de um estímulo constante. É muito comum estarmos sempre nos questionando sobre a decisão que tomamos, acredito que em todos os cursos isso aconteça. Em alguns cursos, o estímulo vem do prestígio que se dá àquela profissão, vem dos pais nos estimulando e elogiando. No curso de Física, esses estímulos dificilmente existem, então, a pessoa precisa de muita conviç̧ão e estímulo próprio, buscando leituras e referências de pessoas ligadas à Física. Muitos cursos e profissões dão recompensas rápidas e fáceis, não é o caso da Física. É preciso um pouco mais de perseverança (P19).

Analisando a perspectiva de (P19) no curso de Física, essa relação com o saber estreita uma condição basicamente interna, já que há pouco estímulo externo para permanecer na graduação em Licenciatura em Física.

Dessa forma, cada um dos 26 egressos buscaram seus elementos externos, mas principalmente interno(s), que pudesse $(\mathrm{m})$ contribuir para a permanência no curso. Nas falas que seguem, quando questionados sobre o que o curso de Física representa ou representou em suas vidas, podemos observar a sensação de estabelecimento da identidade que cada um construiu em sua jornada:

Representa a realização de um sonho pessoal e profissional. Objetivo alcançado com alegria e seguido com prazer até hoje (P3). 
É o meu ganha pão. Mas também nutro uma visão romântica sobre ele. Me fez ser a pessoa que sou boje. Sou muito grato por isso (P5).

Tudo. Tenho orgulho de ser licenciada em Física. Quando perguntam minha formação, primeiro digo Física, depois, Engenharia (P10).

Me ensinou a ser mais cético com relação ao que escuto ou vejo nas notícias, ou mesmo no dia a dia. Tomei gosto pela leitura e pelos estudos e carrego até hoje isso comigo, e posso dizer que isso abriu muitas portas em minha vida. Até hoje estudo física e cosmologia por puro prazer (P11).

Representou amadurecimento intelectual e emocional, representou superação pelas matérias aprovadas, pelo conbecimento adquirido, significon a realização de um sonho (me graduar em Física) (P21).

Em geral, todas as respostas apresentaram forte grau identitário em relação à Física. Nesse caso, podemos dizer que a relação com o saber construída foi frutífera a ponto de, mesmo com as adversidades enfrentadas por cada um, esses egressos tiveram sucesso em sua trajetória e sentem-se pertencentes à área.

\section{Dimensão identitária com a docência}

Contudo, outro ponto importante é o estabelecimento de identidade em relação à docência, exclusivamente. Foi possível identificar que vários docentes (19) se sentiam, em maior ou menor grau, realizados em sua condição profissional atual (professores da Educação Básica ou universitários) ou futura (no caso daqueles que se dedicavam às suas respectivas pós-graduações almejando uma carreira docente no Ensino Superior). Por exemplo, (P5) declara: "eu não sei se conseguiria fazer qualquer outra coisa que não houvesse ensino. Naturalmente, me vejo explicando coisas para meus filhos. Serprofessor é parte de mim". Ou, de forma mais breve, (P13) afirma que ser professor é uma "satisfação". Em sua perspectiva, (P8) afirma que ser professor é "vocação, doação, sacrificio".

Nas falas anteriores, observamos o sentimento de afinidade e identidade à docência. Contudo, alguns egressos (3) também demonstraram certa frustração com a profissão. Porém, nosso instrumento não nos permitiu dimensionar se essa frustração é decorrente de um processo de anos de carreira ou se é algo presente desde sua formação inicial. Sobre isso, (PO) diz que "é bastante responsabilidade. E tem que gostar muito. Porque me parece um trabalho ingrato no Brasil" (P6). Já (P15), afirma que "é algo importante, gosto de ser professor, mas tenho minhas frustrações e tento lidar com elas". Ou ainda, segundo (P11):

Significa ser contratado para o serviço errado. Você ach a que foi contratado para dar aulas de Física mas na verdade será um psicólogo que vai ter que controlar os excessos dos outros sem perder a classe. Irá preparar as aulas e esquecerá de sua tarefa de se preparar para a classe. Só vence nessa profissão quem tem muito amor pelas pessoas e não dá muito valor para o dinheiro e bens materiais (P11).

Mesmo demonstrando algum grau de insatisfação, observamos que os egressos supraditos valorizam a carreira e exaltam que, para exercê-la, é preciso ter amor pela profissão. Em outras palavras, é necessário sentir-se pertencente a um grupo de profissionais que são fundamentais na sociedade contemporânea. 
Em suma, todos os participantes demonstraram, de alguma forma, ter orgulho da profissão de docente de Física. Entendemos que, em linhas gerais, a relação com o saber da Física e da docência foi e é positiva na vida desses profissionais.

\section{Dimensão social}

Outra dimensão da relação com o saber, apontada por Charlot (2000), é a dimensão social. Esta, por sua vez, está atrelada às relações experienciadas com os docentes, com os colegas, com a família, com os determinantes socioeconômicos vividos e de que forma esses pontos interferem na relação com o saber de cada sujeito.

Anteriormente, argumentamos sobre o sentimento de identidade construído em relação à Física por parte dos egressos. Com base nos relatos, podemos inferir que, para alguns (4), esse sentimento tem forte conexão com as convivências ao longo da graduação, como no caso de (P5), que declarou ter construído boas relações com um pequeno grupo de amigos, e que foram fundamentais no seu sucesso no curso:

Alguns são mais próximos e não tentam competir com você no que dì respeito a conbecimento. Esses são especiais. Não brigam ou tiram brincadeiras com você porque tiraram notas maiores que as suas. Auxiliam nas suas dificuldades. Querem que você siga junto com eles ao longo do curso. Te ajudam a crescer (P5).

Em outro exemplo (P10) retrata que aprendeu e valoriza muito sua relação com um de seus professores: "as amizades foram muito importantes. Aprendi muito com professor P[..]. Fiquei no curso porque tinha começado a gostar de Física graças ao projeto". Nesse caso, o projeto em questão é o Labidex, ${ }^{4}$ no qual (P10) foi bolsista.

Charlot (2000) ressalta que as oportunidades no mercado de trabalho e a situação econômica do país também se entrelaçam na dimensão social da relação com o saber. É interessante notar que, dadas as condições de trabalho na rede pública estadual de Santa Catarina, todos os 26 participantes, em algum momento, citaram que a profissão é desvalorizada financeiramente, chegando ao ponto de mencionarem que, nessa profissão, é preciso "ser um idealista" (P24) e que ela é "[...] um trabalho ingrato no Brasil" (P6). Contudo, (P1) lembra que é uma profissão com "ingresso imediato no mercado de trabalbo", mas que apresenta condições precárias de trabalho.

Então, vemos que os determinantes socioeconômicos da dimensão social da relação com o saber dos nossos participantes, apesar de presente, mostrase frágil, pois aparentemente não há maiores incentivos externos para que os estudantes permaneçam e concluam o curso.

Outro elemento ligado à dimensão social é a relação com o outro. A dinâmica do curso de Licenciatura em Física (noturno) não propiciou muitos momentos de convivência fora de situações de sala de aula ou de trabalhos em grupo. Além disso, outros fatores influenciam, tais como os descritos na fala de (P16) reproduzida a seguir:

Esta á uma situação complicada porque as turmas vão se 'esfarelando' ao longo dos anos, devido às desistências, reprovacõoes etc. Mas consegui ficar próximo de uma parcela de colegas - cincoque conseguimos seguir juntos até o final do curso (P16). 
Mesmo entre os quatorze participantes que dizem ter boas ou ótimas relações com os colegas, há uma parcela significativa que ponderou alguns aspectos dessas relações. O principal deles é a construção de vínculos com os colegas. Isso pode ser observado quando os egressos expõem tais elementos: "Tive pouco envolvimento com meus colegas" (P25); ou ainda, "Fizpoucas amizades, mas as que fiz realmente valeram a pena" (P11).

As falas de distanciamento dos colegas foram marcantes entre os egressos do curso. Por outro lado, a relação com outros colegas, mesmo que em número reduzido de indivíduos, foi significativo para a permanência da maioria dos participantes da pesquisa. Arruda e Ueno (2003) alertam para a importância do convívio e da colaboração entre os estudantes. Para os autores, esse é um elemento importante na permanência do curso. Tal aspecto pode ser mais bem observado no seguinte trecho da fala de (P5):

\section{[...] Alguns são mais próximos e não tentam competir com você no que diz respeito ao conhecimento. Esses são especiais: não brigam ou tiram brincadeiras com você porque tiraram notas maiores que as suas, auxiliam nas suas dificuldades; querem que você siga junto com eles ao longo do curso; te ajudam a crescer [...] (P5).}

Sobre os vínculos com os professores, foi possível observar que, em geral, a relação com os professores era "distante e impessoal" (P19). Mesmo entre aqueles que alegavam ter um bom convívio com os docentes do curso: "Minha relação sempre foi cordial, mas sem muita aproximação fora da sala de aula" (P20); em outro caso: "boa, embora superficial" (P24). Esse é um aspecto que, aparentemente, incomodava alguns dos egressos, em particular (P21), ao afirmar que: "com raras exceções”, sua relação com os professores era "muita fria e distante, infelizmente" (P21).

Outro fator relevante na compreensão dos motivos acerca da permanência no curso pelos sujeitos da pesquisa diz respeito à jornada vivida por eles ao longo da graduação. Dos 26 participantes, (12) doze atuavam como docentes durante a Licenciatura, e outros onze trabalhavam em algum projeto dentro da Universidade (Pibid, ${ }^{5}$ Labidex, Iniciação Científica, Baú de Ciências, ${ }^{6}$ entre outros). Esse é um aspecto que evidencia um dos motivos dos altos índices de evasão e repetência no curso, visto que estudantes que não têm a possibilidade de atuar em projetos como os citados anteriormente, normalmente, precisavam conciliar seus estudos com atividades profissionais, o que reduz o tempo de dedicação às atividades discentes.

Cabe ressaltar a importância que a participação em projetos teve na vida de (11) onze egressos pesquisados. O trabalho experienciado por eles foi determinante em diversos segmentos: continuidade nos estudos (Mestrado e Doutorado), atividade profissional (docência e empreendedorismo), aprendizado para as disciplinas do curso, entre outros. Tal aspecto corrobora Stroisch (2012), da Silva (2012) e Parente (2014), pois o suporte da IES, por meio dos projetos, é fundamental, ao passo que permite aos estudantes uma formação mais ampla e propícia, além de outras experiências dentro da instituição, podendo, inclusive, contribuir para a permanência na graduação.

Em outra perspectiva, podemos perceber o fortalecimento da dimensão social da relação com o saber desses estudantes por meio da interação dos grupos dos quais fizeram parte, tal qual podemos perceber na fala de (P17), ao ser questionado sobre a relevância do projeto em que trabalhou (cursinho pré-vestibular da UFSC) e sua permanência no curso o egresso afirma que: "[...] Essa foi a melhor experiência 
de licenciatura na minha vida até hoje, em todos os sentidos. Mas principalmente pela união dos estudantes em torno do projeto. Acreditar que fazíamos a diferença na vida das pessoas". Tivemos ainda a fala de (P21) que sinaliza a importância do Pibid em sua formação:

O PIBID foi fundamental para adquirir alguma prática nas rotinas de uma escola, e também tive muito contato com o conteúdo trabalhado no ensino médio. No projeto fizemos monitoria para os alunos das escolas, preparamos feiras de ciências e até planejamos aulas em laboratório e em sala de aula. Foi fundamental para complementar minha formação e para eu ter uma boa visão do futuro profissional após a faculdade (P21).

Conforme sinalizado por Charlot (2000), a dimensão social vai além da relação entre os sujeitos, ela engloba também as relações dos indivíduos com o mundo. Ao destacar sua participação no cursinho pré-vestibular, (P17) qualifica essa experiência como um dos diferenciais para sua permanência no curso, pois percebia em seu papel como docente (do cursinho) algo que poderia fazer a diferença na vida das pessoas. Podemos indicar algo semelhante para (P21), pois foram as experiências no Pibid que, em sua perspectiva, o aproximaram do mundo profissional que o esperava após a conclusão do curso.

\section{Dimensão epistêmica}

Por fim, a terceira dimensão presente na teoria da relação com o saber é a epistêmica. Uma vez que a dimensão epistêmica trata de uma relação ativa dos sujeitos com os objetos do conhecimento, buscamos centrar nossos questionamentos na relação dos egressos com a Universidade, com o saber físico e pedagógico.

Existe uma aproximação entre a dimensão epistêmica da relação com o saber e as crenças de autoeficácia dos sujeitos (VENTURINI, 2007; SIMÕES, 2018). Uma vez que, ao inferir sobre suas capacidades frente a uma tarefa (autoeficácia), quando essa tarefa passa a ser algo específico dentro do curso de física, por exemplo: resolver uma lista de exercícios de Cálculo, há também um julgamento sobre sua relação com os saberes necessários para desempenhar tal atividade (dimensão epistêmica). Nas falas a seguir podemos observar mais claramente essa aproximação, em particular, quando questionamos os egressos se se consideravam bons estudantes durante o curso: "Não, sempre tive lacunas desde a tenra idade, principalmente ao que concerne ao desenvolvimento matemático" (P1); "Não fui uma boa estudante, porque desde o início não quis realmente o curso de física" (P4). A crença de que não eram bons estudantes interfere na forma com que se relacionam com o conhecimento. Bandura (1997) argumenta que nossas crenças de autoeficácia são construídas, também, por meio das nossas experiências anteriores com àquela atividade ou por comparação com outros indivíduos. De modo semelhante, se considerarmos que (P1) e (P4) não se consideravam bons em tal atividade, podemos dizer que há um distanciamento no aprender em si (CHARLOT, 2000).

Nesse mesmo sentido, vemos outras falas em que a comparação com um referente (pessoal ou de outros sujeitos) mostra-se presente: "Eu me considerava um aluno "médio", nem mediocre nem brilhante" (P16); "Péssimo estudante. Eu não sabia estudar!" (P5). 
Em relação às notas, era mediano. Reprovei pouquíssimas vezes. Tinha dificuldade de aprender os conteúdos, pois não me contentava com as persistentes listas de exercícios que eram dadas! Sempre tentava buscar uma lógica por trás do assunto que me fizesse ter maior fixação. Acho que isso fez. com que minhas notas baixassem em muitas situaçoes, pois despendia um tempo menor nos exercícios dessas listas. Porém, os conteúdos que aprendi nunca mais esqueci e isso foi bom (P11).

Além disso, no caso de (P11), é preciso ponderar que, a forma com que o saber era apresentado a ele, em forma de incansáveis listas de exercício, não permitia que houvesse maior engajamento de sua parte. Retomando Douady (1994), como esse empreendimento (resolver listas de exercícios) não se mostrou significativo para (P11), houve uma rejeição inicial, o que prejudicou suas notas. Mesmo que não declarado, podemos sugerir que (P5) tem um caso semelhante, pois o "não saber estudar" está relacionado a um referencial de (in)sucesso estudantil, o que não foi plenamente alcançado.

Há também aqueles em que a aceitação do saber foi positiva (16). Desse modo, suas crenças de autoeficácia em relação às atividades do curso também se mostraram elevadas: "Sim. Estudava muito, obtive excelentes notas" (P18); "Sim. Obtive bom desempenho acadêmico" (P7).

Outro grupo de egressos apontou que seu desempenho era, de certa forma, controlável (3). Pois sua dedicação podia alternar de acordo com a disciplina: "Era um estudante razoável. Me esforçava o suficiente para terminar o curso" (P20); "Assistia a todas as aulas, mas só estudava o que gostava. Então, depende da disciplina" (P6); "Razoável. Minhas notas eram sempre medianas (a não ser que a matéria me despertasse muito interesse, como em Termodinâmica e Evolução dos Conceitos da Física)" (P25).

Como determinadas disciplinas satisfaziam mais do que outras as necessidades internas dos egressos, pode-se considerar que a relação com o saber que construíam era distinta com cada componente do currículo. Aspecto sinalizado por Douady (1994), ao mencionar que o engajamento é maior no empreendimento se mostrar que "vale mais a pena" para o egresso, não somente do ponto de vista acadêmico, mas também social e cultural, entre outros.

\section{DISCUSSÃO}

Com base nas ponderações desenvolvidas nas categorias de análise apresentadas anteriormente, é possível tecer algumas afirmativas e considerações sobre o estudo desenvolvido. Em relação aos motivos de ingresso no curso, nossos resultados corroboram os trabalhos de Quadros et al. (2005), Simões, Custódio e Rezende-Junior (2016) e Ueno-Guimarães (2013), ao destacarem aspectos de ordem afetiva para tal escolha, tais como a busca por experiências positivas, a paixão e o gosto pela Física, entre outros. Contudo, outros aspectos também foram lembrados, tais como um possível ingresso imediato no mercado de trabalho ou uma adequação à necessidade profissional, fator semelhante ao anunciado em Simões, Custódio e Rezende-Junior (2016), ao destacar que os licenciandos em Física da UFSC consideravam a opção de mercado de trabalho como um dos motivos mais atraentes da carreira de professor de Física. 
No que se refere ao perfil socioeconômico dos egressos, um elemento que destacamos é a presença marcante de indivíduos alegando serem oriundos de famílias com situações econômicas estáveis. Se resgatarmos o que foi assumido por Gatti (2009) e Moreira et al. (2012), o público que está acessando cursos de Licenciatura nos últimos anos pertence, em boa parte, às camadas mais populares da sociedade. Contudo, apenas quatro sujeitos de nossa amostra se autodeclararam em tal condição. Este fato pode ser analisado sob duas perspectivas: na primeira, as respostas fornecidas podem não representar a real totalidade vivida por esses indivíduos ou a pergunta: "Como você avalia a situação socioeconômica da sua família no período do curso?" não foi compreendida totalmente por alguns respondentes; na segunda, podemos considerar que tal parcela da sociedade está pouco representada em nossos resultados, pois esses estudantes abandonaram o curso, ou mesmo não tiveram interesse em participar da pesquisa.

Dessa forma, remetemo-nos a duas análises: uma delas feita por Zago (2006), ao afirmar que, mesmo com o crescente acesso de pessoas oriundas de camadas mais populares da sociedade, o maior desafio desses sujeitos é completar o curso, vide as mais diversas adversidades enfrentadas ao longo da graduação; ou ainda, segundo Mendes e Costa (2015), mesmo com a mudança no perfil dos ingressantes nos cursos de graduação, a parcela da sociedade que predomina ainda é aquela formada por sujeitos de famílias com certa estabilidade econômica.

Ainda em relação aos aspectos do seio familiar, destacamos, relativamente, o alto nível de escolaridade familiar dos egressos. Visto que tanto os pais (treze pais e dez mães) quanto os irmãos (vinte) apresentaram, em grande parte, curso superior completo. Esse aspecto pode estar relacionado ao fato de os licenciados declararem que, em geral, recebiam apoio familiar para cursarem a graduação. Contudo, o receio quanto ao curso ainda é presente, especialmente no que diz respeito aos fatores econômicos e ao baixo prestígio social da profissão.

No bojo da permanência no curso, não podemos deixar de destacar as relações interpessoais vividas ao longo do curso. Em destaque para as falas que demonstraram a importância do convívio com os colegas de curso para a permanência. Assim como aquelas que destacaram a influência da relação entre professor e aluno na construção de vínculos duradouros com o curso. Dessa forma, nossos dados corroboram com Arruda e Ueno (2003) no que se refere à influência desses grupos na permanência (ou não) na Licenciatura; além disso, podemos complementar salientando que as experiências positivas fortaleceram a relação com o saber desses egressos, uma vez que esta é construída ao longo da relação com o mundo e com o outro (CHARLOT, 2000).

Cabe ressaltar que, praticamente de modo unânime, foi sinalizado que a relação de afastamento dos docentes não é entendida como positiva pelos egressos. Nossos dados revelaram que posturas de arrogância e distanciamento são, além de indesejadas, fatos que podem gerar abandono, como no caso de (P4), que mudou de Universidade, ou de (P23), que alterou a habilitação do Bacharelado para a Licenciatura.

Outro ponto importante evidenciado em nossa análise é a construção de uma identidade por parte dos egressos em relação ao curso e à docência, fator citado por Silva (2013) como relevante no estabelecimento da relação com o saber. Além disso, o discurso dos egressos de que não há muitos estímulos externos para 
a conclusão de uma graduação em Licenciatura em Física, que esses vêm de dentro. Tal ponto corrobora o entendimento de Charlot (2000) quanto ao papel do desejo na mobilização dos sujeitos. Complementamos, ainda, que, mesmo que esse desejo seja algo interno e que mobilize os estudantes, não podemos descartar a influência dos aspectos externos (presentes na relação com o mundo e com o outro), que podem contribuir para persistência ou desistência na busca de um objetivo.

Sobre a dimensão social da relação com o saber, destacamos a relação do trabalho na vida desses egressos. Todos, em algum momento, citaram a desvalorização da carreira docente, em particular, na rede pública estadual de Santa Catarina. Dessa forma, no que concerne à relação com o mundo do trabalho, a relação com o saber torna-se frágil. Porém, devemos lembrar que, em alguns momentos, essa dimensão foi destacada de forma a positivar, algo perceptível quando sujeitos citam suas relações positivas com colegas e professores do curso.

Sobre a dimensão epistêmica ligada ao conhecimento, o destaque ficou a cargo do entendimento dos licenciados e licenciadas de que seu desempenho no curso, por vezes, era satisfatório ou bom. Esse aspecto sinaliza o fato de os egressos perceberemse com dificuldades, devido aos mais diversos motivos, por exemplo: não saber estudar.

Douady (1994) argumentou que o engajamento dos estudantes é maior em atividades nas quais eles percebem-se aptos; ou seja, que suas crenças de autoeficácia são elevadas. Tal aspecto não permeou a fala de todos os sujeitos, mesmo sendo um grupo de egressos do curso (situação que poderíamos indicar como de sucesso). Os resultados nos diferentes testes (provas, trabalhos, seminários etc.), por vezes negativos, não foram suficientes para que desistissem do curso. Contudo, há relatos sobre diversos de seus colegas de graduação que o fizeram.

Assim, o aspecto interno da motivação ou a mobilização mostra-se fator crucial na permanência no curso. Especialmente no que consiste às expectativas de mercado de trabalho, pois, apesar das críticas, os licenciados e licenciadas ressaltaram a qualidade da formação ofertada pela IES, mas teceram ressalvas quanto à conexão com a Educação Básica, especialmente os egressos anteriores a 2009 (ano da última mudança no currículo do curso). Esse aspecto vai ao encontro do que afirmaram Bicalho e Souza (2014), ao descreverem a dinâmica da relação com o saber com o desenvolvimento pessoal, visto que os egressos consideram que sua formação os permite atuar de forma contundente no mercado de trabalho.

A partir desses resultados construímos um quadro síntese com os principais aspectos levantados como motivos para a permanência no curso: 
Quadro 2. Síntese dos elementos da relação com o saber relativos à permanência no curso

\begin{tabular}{|c|c|}
\hline Dimensão epistêmica & $\begin{array}{l}\text { - Relacionam a aprendizagem, quase que } \\
\text { exclusivamente, aos resultados em testes. }\end{array}$ \\
\hline Dimensão identitária & $\begin{array}{l}\text { - Estabelecimento de uma identidade com o curso. } \\
\text { - Estabelecimento de uma identidade com a docência. }\end{array}$ \\
\hline $\begin{array}{l}\text { Dimensão social: relação } \\
\text { com o mundo, aspectos } \\
\text { socioeconômicos }\end{array}$ & $\begin{array}{l}\text { - Apoio dos colegas para permanecer no curso. } \\
\text { - Importância dos projetos: Pibid, Labidex, IC etc. } \\
\text { - Situação econômica estável. } \\
\text { - Escolaridade elevada na família. } \\
\text { - Desejo de ter uma relação mais próxima com os } \\
\text { professores formadores. }\end{array}$ \\
\hline $\begin{array}{l}\text { Aspectos afetivos (transversais } \\
\text { às dimensões) }\end{array}$ & $\begin{array}{l}\text { - Motivação pessoal. } \\
\text { - Crenças de autoeficácia mais elevadas. } \\
\text { - Buscaram o curso para reviver experiências } \\
\text { emocionais positivas. }\end{array}$ \\
\hline
\end{tabular}

Fonte: os autores

Por fim, percebemos que os sujeitos atribuem seu sucesso enquanto concluintes do curso a fatores internos e controláveis (motivação, persistência, dedicação). Além disso, a relação com o saber da Física foi construída especialmente por fatores internos, haja vista que, em alguns momentos, os egressos citaram aspectos que os desmotivaram a prosseguir no curso. Assim, percebemos que a relação consigo, com o outro e com o mundo, citada por Charlot (2000), é evidenciada em diversos pontos da análise.

\section{ALGUMAS CONSIDERACְ̃̃ES}

Dessa forma, declaramos que a permanência no curso de Licenciatura em Física da UFSC por parte dos sujeitos egressos esteve atrelada a fatores como: motivação pessoal e interna, em contraste com as adversidades externas; estabelecimento de uma identidade com a área, em relação à Física ou à docência em Física; e suporte da Universidade, principalmente, por meio de projetos como o Pibid, Labidex, Baú de Ciências e outros.

Entre os fatores citados, destaca-se a relação identitária com o saber. Ao perceberem-se como integrantes de um grupo, que tem demarcadas suas tradições, procedimentos e saberes, os egressos estabeleceram relações de identidade, que foram importantes também nas relações sociais e epistêmicas que desenvolveram. Podemos dizer que a relação identitária, apesar de não ser superior às outras, atuou como elo entre as demais. Alguns elementos citados pelos egressos - a pouca valorização da carreira de professor e a relação pouco amistosa com os professores (relação social); aqueles que lembraram que, por vezes, não foram estudantes de destaque, mas sim "medianos" ou que o curso não prepara totalmente para a 
realidade da escola, o que reflete numa crítica ao aspecto formativo da Licenciatura (relação epistêmica) - exprimem relações que não dão conta de explicar porque eles, enquanto estudantes, permaneceram no curso. Por isso, entendemos que o elo principal está na relação identitária.

A relação com o saber se dá em três dimensões (epistêmica, social e identitária). Ter um curso com foco em apenas uma delas (epistêmica) talvez não seja tão efetivo quanto se deseja. Repensar alguns pontos dos cursos de graduação poderia ser um importante passo no sentido de potencializar a permanência dos estudantes até a conclusão do curso. Fazer os licenciandos se sentirem pertencentes ao universo da docência em Física (dimensão identitária), com ações como fornecer uma melhor acolhida nos primeiros anos de curso, além de propiciar condições de permanência por meio de projetos de pesquisa e de extensão (dimensão social), mostrou-se como elemento efetivo para permanência no curso junto ao público pesquisado. A ampliação de ações dessa natureza poderiam garantir um número maior de egressos nos cursos de Licenciatura em Física.

\section{REFERÊNCIAS}

ANAHÍ DA SILVA, V. Conexões de saberes: um desafio e uma aventura institucional e política. In: ANAHÍ DA SILVA, V. (Org.). Conexões de saberes: um desafio, uma aventura, uma promessa. São Cristóvão: UFS, 2007.

ARRUDA, S. M.; UENO, M. Sobre o ingresso, desistência e permanência no curso de física da Universidade Estadual de Londrina: algumas reflexões. Ciência \& Educação, v. 9, n. 2, p. 159-175, 2003. Disponível em: <http://www.scielo.br/pdf/ciedu/v9n2/02.pdf >. Acesso em: mar. 2019.

BANDURA, A. Self-efficacy in changing societies. Cambridge: Cambridge University Press, 1997.

BICALHO, M. G. P.; SOUZA, M. C. R. F. Relação com o saber de estudantes universitários. Educ. Pesqui., São Paulo, v. 40, n. 3, p. 617-635, 2014. Disponível em: < http://www.scielo.br/pdf/ep/ v40n3/aop1424.pdf>. Acesso em: mar. 2019.

CHARLOT, B. Da relação com o saber: elementos para uma teoria. Porto Alegre: Artmed Editora, 2000.

CHARLOT, B. Relação com o Saber, formação dos professores e Globalização, Questões para a educação hoje. Porto Alegre: Artmed Editora, 2005.

CISLAGHI, J. F. Análise do Reuni: uma nova expressão da contra-reforma da universidade brasileira. Dissertação (Mestrado em Serviço Social). Universidade do Estado do Rio de Janeiro - UERJ, Rio de Janeiro. 190p., 2010. Disponível em: < http://flacso.redelivre.org.br/files/2012/07/433.pdf>. Acesso em: mar. 2019.

CUNHA, A. M.; TUNES, E.; SILVA, R. R. da. Evasão do curso de Química da Universidade de Brasília: a interpretação do aluno evadido. Quim. Nova, v. 24, n. 1, p. 262-280, 2001. Disponível em: < http://www.scielo.br/pdf/qn/v24n2/4291.pdf>. Acesso em: mar. 2019.

da SILVA, S. S. Trajetória de estudantes da rede pública que ingressaram, permanecem e obtém êxito numa universidade pública. Dissertação (Mestrado em Educação). Universidade Federal do Rio Grande no Norte - UFRN. Natal, 146p., 2012. Disponível em: < https:/ / repositorio. ufrn.br/jspui/bitstream/123456789/14524/1/SilciaSS_DISSERT.pdf>. Acesso em: mar. 2019 
DOUADY, R. Evolução da relação com o saber em Matemática na escola primária: uma crônica sobre cálculo mental. Em Aberto, Brasília, ano 14, n. 62, 1994. Disponível em: < http://rbep.inep. gov.br/index.php/emaberto/article/viewFile/1962/1931>. Acesso em: mar. 2019.

FEITOSA, L. D. A escolha pela licenciatura em física - uma análise a partir da Teoria da Relação com o Saber. Revista Ensaio, v.15, n. 03, p. 235-251, 2013. Disponível em: <http://www.scielo.br/ pdf/epec/v15n3/1983-2117-epec-15-03-00235.pdf>. Acesso em: mar. 2019.

GATTI, B. A. Atratividade da carreira docente no Brasil: relatório parcial de pesquisa. São Paulo: Fundação Carlos Chagas; Fundação Vitor Civita, 2009. Disponível em: < http://revistaescola.abril. com.br/pdf/relatorio-final-atratividade-carreira-docente.pdf>. Acesso em: 12 mai. 2013.

KUSSUDA, S. R. Um estudo sobre a evasão em um curso de Licenciatura em Física: discursos de ex-alunos e professores. 2017. 307f. Tese (Doutorado em Educação para a Ciência). Faculdade de Ciências. Universidade Estadual Paulista - UNESP. Bauru, 2017. Disponível em: < goo.gl/ XAaSQf $>$. Acesso em: mar. 2019.

KUSSUDA, S. R.; A escolha profissional de licenciados em Física de uma universidade pública. Dissertação (Mestrado em Educação para a Ciência). Universidade Estadual Paulista UNESP, Bauru. 185p., 2012. Disponível em: < goo.gl/4cxxLo>. Acesso em: mar. 2019.

LIMA JUNIOR, P.; OSTERMANN, F.; REZENDE, F. Análise dos condicionantes sociais da evasão e retenção em cursos de graduação em Física à luz da sociologia de Bourdieu. Revista Brasileira de Pesquisa em Educação em Ciências, v. 12, n. 1, 2012. Disponível em: < http://www.scielo.br/ pdf/epec/v15n1/1983-2117-epec-15-01-00113.pdf>. Acesso em: mar. 2019.

MENDES, I. A. A.; COSTA, B. L. D. Considerações sobre o papel do Capital Cultural e acesso ao ensino superior: uma investigação com dados de Minas Gerais. Educ. rev. V.31, n.3, 2015. Disponível em: < http://www.scielo.br/pdf/edur/v31n3/0102-4698-edur-135457.pdf>. Acesso em: mar. 2019.

MORAES, R.; GALIAZZI, M. do C. Análise textual discursiva. Ijuí: Editora UNIJUÍ, 224 p., 2007.

MOREIRA, P. C.; FERREIRA, E. B.; JORDANE, A.; NOBRIGA, J. C. C.; FISCHER, M. C. B.; SILVEIRA, E.; BORBA, M. C. Quem quer ser professor de Matemática? Zetetiké, v. 20, n. 37, 2012. Disponível em: < goo.gl/ETHoAN>. Acesso em: mar. 2019.

PARENTE, N. N. As condições de acesso e permanência dos estudantes do curso de Licenciatura em Física do IFCE, câmpus de Sobral. Dissertação (Mestrado em Políticas Públicas e Gestão da Educação Superior). Universidade Federal do Ceará - UFC. Fortaleza, 168p., 2014. Disponível em: < http://www.repositorio.ufc.br/bitstream/riufc/10551/1/2014_dis_nnparente. pdf>. Acesso em: mar. 2019.

QUADROS, A. L. de, et al. Os professores que tivemos e a formação da nossa identidade como docentes: um encontro com nossa memória. Revista Ensaio, Vol. 7 n 01, Belo Horizonte, 2005. Disponível em: < http://www.scielo.br/pdf/epec/v7n1/1983-2117-epec-7-01-00004.pdf>. Acesso em: mar. 2019.

SILVA, L. S. C. da. Jovens universitários e sua relação com o saber. Dissertação (Mestrado em Psicologia). Universidade Federal da Bahia - UFBA. Salvador, 2013. Disponível em: < goo.gl/ xBofAJ>. Acesso em: mar. 2019.

SIMÕES, B. S. Relações com o saber no curso de Licenciatura em Física da UFSC: passado e presente da evasão e permanência. 2018. 277f. Tese (Doutorado em Educação Científica e Tecnológica) - Centro de Ciências da Educação, Universidade Federal de Santa Catarina, Florianópolis, 2018. 
SIMÕES, B. S.; CUSTÓDIO, J. F.; REZENDE-JUNIOR, M. F. Motivações de licenciandos para escolha da carreira de professor de Física. Revista Brasileira de Pesquisa em Educação em Ciências. v. 16, n. 1, 2016.

STROISCH, A. A permanência e o êxito dos alunos cotistas dos cursos superiores do câmpus São José do Instituto Federal de Santa Catarina (2009 - 2010). Dissertação (Mestrado em Educação). Universidade Estadual de Câmpusnas - UNICAMP, Câmpusnas. 233p., 2012. Disponível em: < http://repositorio.unicamp.br/jspui/bitstream/REPOSIP/250909/1/Stroisch_Adriane_M. pdf>. Acesso em: mar. 2019.

UENO-GUIMARÃES, M. A escolha pela Física: gosto ou desafio? Tese (Doutorado em Educação). Universidade de São Paulo - USP. São Paulo, 233p., 2013. Disponível em: http://www. teses.usp.br/teses/disponiveis/48/48134/tde-28012014-095232/pt-br.php>. Acesso em: mar. 2019.

VENTURINI, P. The Contribution of the Theory of Relation to Knowledge to Understanding Students' Engagement in Learning Physics. International Journal of Science Education, v. 29, n. 9, p. 1065-1088, 2007. Disponível em: < https://www.tandfonline.com/doi/ abs/10.1080/09500690600855880>. Acesso em: mar. 2019.

ZAGO, N. Do acesso à permanência no ensino superior: percursos de estudantes universitários de camadas populares. Revista Brasileira de Educação, v. 11, n. 32, 2006. Disponível em: < http:// www.scielo.br/pdf/rbedu/v11n32/a03v11n32.pdf>. Acesso em: mar. 2019.

\section{NOTAS}

1 Departamento das Ciências da Educação da Universidade de Paris-VIII, Saint-Denis.

2 Idade em 2015.

3 Currículo vigente em 2018.

4 O Laboratório de Instrumentação, Demonstração e Exploração (Labidex) é um espaço destinado a vivenciar a ciência por meio de atividades experimentais participativas.

5 Programa Institucional de Bolsas de Iniciação à Docência.

6 Projeto de extensão voltado à divulgação científica por meio de oficinas e jogos oferecidos na Universidade ou nas escolas.

Submetido em 12/03/2019

Aprovado em 12/03/2020

\section{Contato:}

Faculdade de Ciências Exatas e Tecnologia - FACET

Programa de Pós-Graduação em Ensino de Ciências e Matemática - PPGECMat

Rodovia Dourados/ltahum, Km 12 - Unidade II | Caixa Postal: 364

CEP 79.804-970 - Dourados, MS - Brasil 